Understanding digital dating abuse from an evolutionary perspective: Further evidence for the role of mate value discrepancy

Manpal Singh Bhogal (‥s.b2@wlv.ac.uk)*, Courtney Rhead \& Courtney Tudor

*ORCID: 0000-0002-7913-0726 (corresponding author)

Department of Psychology, Evolution and Human Behaviour Research Group, University of Wolverhampton, WV1 1LY, UK

Acknowledgments: We thank Janine Hall and Aleema Hussain for collecting part of the data for study 2 . 


\begin{abstract}
Decades of research have been dedicated to understanding intimate partner violence. A recent form of intimate partner violence is digital dating abuse, which involves electronic intrusion in romantic relationships. Previous research has focused on the effects of digital dating abuse on victims, yet little research has focused on the factors which drive the perpetration of digital dating abuse, especially from an evolutionary perspective. Recent research has focused on whether mating-relevant factors such as mate value discrepancy predict the perpetration of digital dating abuse, suggesting digital dating abuse could be a mate retention tactic. Here, we replicated and extended that finding in two independent samples (study 1, $n=177$; Study 2, $n=134$ ) by showing large mate value discrepancies positively predict digital dating abuse, therefore suggesting that digital dating abuse could be a contemporary cost-inflicting mate retention strategy. We also explored whether intrasexual competition, self-esteem, and experience of previous infidelity predicted the perpetration of digital dating abuse, finding no significant relationships. These findings from two studies, replicate, extend, and provide further support that digital dating abuse is a mate retention tactic. This research advances our understanding of digital dating abuse from an evolutionary psychological perspective.
\end{abstract}

Keywords: mate retention; digital dating abuse; cyber dating abuse; intrasexual competition; mate value discrepancy 


\section{Understanding digital dating abuse from an evolutionary perspective: Further support for the role of mate value discrepancy}

\section{Digital dating abuse}

Intimate partner violence (IPV) has gained the attention of researchers for decades in the behavioral sciences. According to the World Health Organisation (2012), IPV encompasses emotional, sexual, and physically controlling behaviors towards a romantic partner. Since IPV can be multifaceted, in that it can involve several predictive factors, it is important to be able to disentangle the key factors driving various forms of IPV (Brown \& Hegarty, 2018).

A relatively new form of IPV is a coin termed digital dating abuse, which has only recently been given scholarly attention. Digital dating abuse refers to the use of digital mediums to control, harass, or to display aggressive type behaviors towards a romantic partner, which can be direct and indirect (Melander, 2010). This form of intimate partner violence is problematic, particularly as digital dating abuse does not require physical proximity as with traditional forms of partner-directed abuse which occur offline (Zweig, Dank, Yahner, \& Lachman, 2013). Digital dating abuse occurs through the use of electronic information technology, often including social media platforms and messaging applications, making it distinct from offline partner-directed abuse, as anonymity can be easily obtained in online abuse compared to offline abuse (Melander, 2010). Furthermore, as digital dating abuse leads to negative outcomes in its victims, particularly negative mental health outcomes (Fahy et al., 2016; Stonard, Bowen, Walker, \& Price, 2017), it is important to empirically explore factors which drive digital dating abuse.

From the pool of literature, we can see that scholars have empirically shown that traits such as hostility, behavioral jealousy, and attachment anxiety predict the perpetration of digital dating abuse (Bhogal \& Howman, 2019; Deans \& Bhogal, 2017; Reed, Tolman, \& Safyer, 2015; Reed, Tolman, Ward, \& Safyer, 2016). In regards to gender, research has provided mixed 
support, with some research suggesting men engage in digital dating abuse to a greater degree than women, that women engage in more electronic intrusion than men, and some research finding no sex differences (see Bhogal \& Howman, 2019; Burke, Wallen, Vail-Smith, \& Knox, 2011; Deans \& Bhogal, 2017; Graham-Kevan \& Archer, 2009; Reed, Tolman, \& Ward, 2017). Effect sizes found in previous studies exploring gender and digital dating abuse have ranged from small to medium effect sizes, according to Cohen's $f^{2}$ (Bhogal \& Howman, 2019; Deans \& Bhogal, 2017; also see Selya, A. S., Rose, J. S., Dierker, L. C., Hedeker, D., \& Mermelstein, 2012 for a discussion on using Cohen's $f^{2}$ )

\subsection{Digital dating abuse as mate retention}

A key focus of this paper was to explore mating-relevant factors which could drive digital dating abuse, with one of those being mate value. Mate value refers to the sum of traits we possess which display reproductive fitness, encompassing physical, social and psychological characteristics such as physical attractiveness, being outgoing, and wanting a home and children (Buss \& Barnes, 1986; Keys \& Bhogal, 2018). High mate value (i.e those who possess most of these traits) refers to those who possess high-quality traits which are desirable in mate choice. Mate value discrepancy refers to the difference in mate value between ourselves and our current romantic partner (Bhogal \& Howman, 2019). Mate value discrepancy predicts several relationship outcomes such as forgiveness, jealousy (Sidelinger \& BoothButterfield, 2007), and general mate retention tactics (Buss \& Shackelford, 1997; Sela, Mogilski, Shackelford, Zeigler-Hill, \& Fink, 2017), signifying the importance mate value has on the functionality of romantic couples.

When maintaining a romantic relationship, one key facet and goal is to deter potential romantic rivals, in turn decreasing the chance of infidelity occurring in the relationship (Shackelford, Goetz, \& Buss, 2005). These pressures have given rise to mate retention tactics, 
often employed to reduce the likelihood of infidelity and to reduce the likelihood of mate poaching. For example, research shows that those who have high mate value engage in mate poaching more often than those of lower mate value (Erik \& Bhogal, 2016). The consequences of mate poaching have been outlined in previous research showing mate poaching is an important part of romantic relationships. For example, some use exploitation and manipulation to increase their mating success (Buss \& Duntley, 2008). Furthermore, if those in romantic relationships do not engage in mate guarding, there is greater risk of a mate being poached or leaving the relationship, which signifies the importance of mate retention and mate guarding behaviors (Jonason, Li, \& Buss, 2010). In response to the risks associated with mate poaching and partner-infidelity, humans have developed mate retention strategies (Bhogal \& Howman, 2019; Buss, 1988). These mate retention tactics can comprise of cost inflicting mate retention behaviors (control, manipulation, and general negative behaviors directed to a partner, Albert \& Arnocky, 2016) and benefit-provisioning mate retention behaviors (positive acts such as giftgiving and compliments directed towards a partner) with the aim of maintaining the relationship (Atari, Barbaro, Shackelford, \& Chegeni, 2017; Lopes, Shackelford, Santos, Farias, \& Segundo, 2016). Furthermore, cost-inflicting mate retention behaviors can often take the form of abuse, directed towards a partner, with a general aim to make it difficult for a partner to leave the relationship (Miner, Starratt, \& Shackelford, 2009). Finally, cost-inflicting mate retention behaviors are characterised by control, isolating one's partner and general threat directed towards a romantic partner (Graham-Kevan \& Archer, 2009; Miner et al., 2009).

In support, and extending these findings to explore both mate value and mate guarding, Danel et al. (2017) found that when women were asked to rate the prevalence of controlling behaviors in their current romantic relationship, the prevalence of controlling, or mate guarding behaviors from their partners was higher when the participant (women) was of higher mate value compared to the male. Furthermore, the level of controlling behaviors was similar in 
which women reported higher mate value discrepancies between themselves and their partner. The above study explored the role of mate value discrepancy in mate guarding tactics across a variety of dimensions, which can be applied to digital dating abuse. For example, digital dating abuse can be characterised as encompassing coercion, intimidation, and emotional abuse, which were all explored in the study by Daniel et al. (2017). A relatively recent hypothesis put forward by Bhogal and Howman (2019) is that those in romantic relationships may use digital mediums to engage in cost-inflicting mate retention and mate guarding. Bhogal and Howman (2019) found that the discrepancy between participants' own mate value and the mate value of their partners positively predicted the perpetration of digital dating abuse, in that participants were more likely to engage in digital dating abuse if they reported higher discrepancies between themselves and their partner, i.e if their partners were of a higher mate value compared to themselves. They argue that because high-quality mates are difficult to replace, those who view their partners as having higher mate value compared to themselves will engage in greater levels of digital dating abuse to retain their mate.

The link between digital dating abuse and cost-inflicting mate retention behaviors are evident by the fact that both involve the use of control to maintain a relationship, reducing the likelihood of infidelity, mate poaching, and a partner defecting from the relationship (Bhogal \& Howman, 2019; Brem, Spiller, \& Vandehey, 2015). These associations make studying digital dating abuse as a mate retention behavior an important area for evolutionary psychologists and cyberpsychologists.

\subsection{Exploratory mating-relevant factors}

As well as exploring the role of mate value discrepancy, we explored the role of intrasexual competition in digital dating abuse. Intrasexual competition refers to intrasexual rivalry which occurs between same-sex individuals for potential mates, with the ultimate aim 
of maximizing reproductive success (Buss, 2006; Darwin, 1871). Previous research shows that intrasexual competition is related to mate retention behaviors (Arnocky, Sunderani, \& Vaillancourt, 2013; Karimi-Malekabadi \& Esmaeilinasab, 2019). Furthermore, intrasexual competition not only occurs before the beginning of a relationship, but continues during a relationship to maintain and defer romantic rivals (Keys \& Bhogal, 2018), showing that mate retention occurs throughout a relationship. Furthermore, due to the scarcity of mates, intrasexual competition can lead to mate guarding behavior (Arnocky, Ribout, Mirza, \& Knack, 2014). Research shows that both men and women engage in intrasexual competition when guarding mates, including extreme forms of guarding such as violence (Daly \& Wilson, 1988) and more milder forms such as direct and indirect aggression (Keys \& Bhogal, 2018), which are activated by mating motives (Vaillancourt, 2013).

As a result of the mate guarding nature of intrasexual competition, it is surprising that researchers have not explored the role intrasexual competition plays when monitoring a partner in the digital world, particularly as digital communication is so prevalent in our daily lives. If intrasexual competitiveness deters potential romantic rivals and mate poachers, it is sensible to suggest that digital dating abuse could be a contemporary mate retention behavior to deter potential romantic rivals from one's partner. Therefore, if digital dating abuse is a costinflicting mate retention behavior, then we would expect intrasexual competition to play a part in driving the perpetration of digital dating abuse. As a result, we explored the role of intrasexual competition in digital dating abuse.

The link between self-esteem and digital dating abuse was also explored in this study. As mate retention behaviors can sometimes be cost-inflicting, these techniques can also involve lowering a partners self-esteem to maintain the relationship, thus deterring a partner from leaving the relationship (Miner et al., 2009). In support, mate retention behaviors have been found to correlate with self-esteem, suggesting those who have lower self-esteem tend to 
engage in greater cost-inflicting mate retention behaviors (Holden et al., 2014). Also, those who have higher self-esteem tend to engage in more benefit-provisioning mate retention tactics (Atari, Barbaro, Shackelford, et al., 2017). On the other hand, those who have low self-esteem tend to engage in greater levels of partner directed derogation than those who have high selfesteem (Murray, Rose, Bellavia, Holmes, \& Kusche, 2002) and digital dating abuse does encompass derogation of a romantic partner. When exploring mate retention behaviors, previous research has found that those with higher self-esteem do engage in less cost-inflicting mate retentions, signifying the role of self-esteem in mate retention (Zeigler-Hill, Fulton, \& Mclemore, 2011; Zeigler-Hill, Fulton, \& McLemore, 2012).

If digital dating abuse is a mate retention, or mate guarding behavior, then it is plausible to suggest that self-esteem would be related to electronic intrusion due to seeking cues of infidelity. The fact that low self-esteem has been found to predict offline dating violence in women (Lewis, Travea, \& Fremouw, 2002), it is important to explore whether this finding (in general) replicates in the digital world, especially as partner-perpetrated abuse is rapidly changing due to the use of digital mediums.

As an exploratory variable, we explored whether having experience of sexual infidelity would be related to the perpetration of digital dating abuse. Being cheated on can lead to several negative outcomes such as relationship dissolution, reduced health, and poor mental health (Rhoades, Kamp Dush, Atkins, Stanley, \& Markman, 2011). Perhaps the experience of reduced self-esteem (from being on the receiving end of infidelity) could be creating a feedback loop of poor self-esteem, which may lead to digital dating abuse. This, therefore, shows the importance of exploring whether experienced sexual infidelity is related to the perpetration of digital dating abuse. Furthermore, Bhogal and Howman (2019) suggest that research exploring the perpetration of digital dating abuse should explore whether having experience of sexual infidelity in past relationships is associated with digital dating abuse. They argue that those 
who have been cheated on by previous partners may be more susceptible to cues of infidelity, and may search for those cues to a greater degree than those who have not been cheated on. In support, Marr, Thau, Aquino, and Barclay (2012) found that when individuals have been harmed by a group member, they are hyper-vigilant to relationship-threatening cues, which could be applied to digital dating abuse and romantic couples. If those who have been harmed (cheated on) by a romantic partner in the past, they could be more vigilant to cues of infidelity.

\subsection{Aims and hypotheses}

The primary aims of this paper were to 1) to assess whether mate value discrepancy was positively related to digital dating abuse in two independent samples and 2) to explore additional mating-relevant factors of digital dating abuse (intrasexual competition, self-esteem, and experience of sexual infidelity).

We hypothesised the following:

A priori hypothesis 1: Mate value discrepancy would positively predict digital dating abuse, in that higher mate value discrepancy would be positively related to higher digital dating abuse (Study 1 and 2)

Exploratory hypothesis 2: Intrasexual competition would be related to digital dating abuse (Study 2).

Exploratory hypothesis 3: Self-esteem would be related to digital dating abuse (Study 2).

Exploratory hypothesis 4: Experience of sexual infidelity would be related to digital dating abuse (Study 2). 


\section{Study 1}

\subsection{Method}

\subsubsection{Design and participants}

A correlational design was adopted to explore whether mate value discrepancy was related to the perpetration of digital dating abuse. The sample consisted of 177 heterosexual people (131 women, 46 men, Mage $=26.73$ years old, $S D=9.36)$ from the general public in the United Kingdom, recruited via Qualtrics which is an online survey builder). Participants took part via survey links shared on social media sites such as Twitter and Facebook. Participants were required to be English speaking, due to the survey being presented in English. All participants consented online. Participants were required to currently be in a romantic relationship (Mrelationship length $=52.20$ months, $S D=109.18$, Median $=20$ ).

To guide our anticipated sample size, an a-priori power analysis was conducted using G*Power (Faul, Erdfelder, Buchner, \& Lang, 2009). To achieve 80\% power (medium effect size of .15 with 1 predictor, and an alpha level of .05 - all for linear regression), G*Power recommended 55 participants, which we surpassed. Effect sizes for study 1 and 2 were based on Bhogal and Howman (2019).

\subsection{Materials}

\subsubsection{Mate Value}

The 17-item Mate Value Inventory Short Form (Kirsner, Figueredo, \& Jacobs, 2003) was used to measure the participants' self-perceived mate value, and that of their current partner. The scale lists characteristics which are scored on a 7-point Likert scale ranging from "-3 = Extremely low on this characteristic" to " $+3=$ Extremely high on this characteristic". Consistent with Bhogal and Howman (2019), these values were altered (for study 1 and 2) to 1 (extremely low) and 7 (extremely high) to make the scale easier to complete for our 
participants. High scores reflect high mate value, and low scores reflect low mate value. Example items include "attractive face" and "financially secure". For study 1 and 2, participants completed this scale twice, once where they rated themselves, and one where they rated their partner (counterbalanced through the randomizer function on Qualtrics). For reliability analyses, Cronbach's alpha values were reported in study 1 and 2 (for all scales). This scale was reliable in our sample (self-mate value, $\alpha=.87$ and partner mate value, $\alpha=.91$ ). For studies 1 and 2, mate value discrepancy was calculated by computing the difference between self and partner mate value scores (consistent with Bhogal \& Howman, 2019).

\subsubsection{Digital Dating Abuse}

We used the 19-item perpetration sub-scale of the Digital Dating Abuse scale, which measures participants' experiences of perpetrating digital dating abuse towards their partner (Reed et al., 2016). Participants scored each item by how often they have carried out each behavior towards their current partner, on a 4-point Likert scale ranging from " $0=$ Never" to “3 = Very often". An example item is "Looked at my partner's private information on a computer or mobile phone without permission". Higher scores reflected greater perpetration of digital dating abuse, and low scores reflect low perpetration of digital dating abuse. The scale had acceptable reliability in our sample $(\alpha=.66)$.

\section{3. Procedure}

For studies 1 and 2, once participants provided informed consent, they were asked to provide demographic details and complete the questionnaires outlined above, and in the materials section of study 2. Finally, participants were fully debriefed. Data were collected anonymously, online, using Qualtrics. For studies 1 and 2, the order of questionnaires was counterbalanced using the randomizer function on Qualtrics. 


\section{Results}

Linear regression was conducted to predict the perpetration of digital dating abuse from mate value discrepancy. All analyses in this paper were performed using JASP (JASP team, 2018). Values derived from the analyses are presented in Table 1. Hierarchical linear regression was conducted to predict perpetration of digital dating abuse (mean $=21.84, S D=2.77)$ from mate value discrepancy ${ }^{1}$ (mean difference $=-.4 .80, S D=12.51$ ) whilst controlling for age and sex.

Age and sex were added to block 1 of the model. Here, they accounted for $1.1 \%$ of the variance in digital dating abuse (adjusted $\left.R^{2}=-.001\right), F(2,174)=.947, p=.390$. Mate value discrepancy was added to block 2 of the model. This resulted in a $R^{2}$ change of .046 and a statistically significant $F$ change (.004).

The final model explained $5.7 \%$ of the variance in digital dating abuse, $F(3,173)=$ 3.49 (adjusted $\left.R^{2}=.041\right), p=.017$, Cohens $f^{2}=.060$, Durbin-Watson $=1.94$. Mate value discrepancy significantly, positively predicted digital dating abuse, supporting hypothesis 1 . VIF and Tolerance values in Table 1 show that there was no multicollinearity in our model, as values were close to 1, as recommended by Pallant (2016).

\footnotetext{
${ }^{1}$ Self-mate value $=100.56(S D=14.69$. Partner mate value $=105.36(S D=17.48)$.
} 
Table 1: Results of the hierarchical linear regression model predicting digital dating abuse from mate value discrepancy.

\begin{tabular}{|c|c|c|c|c|c|c|c|}
\hline \multirow[t]{2}{*}{ Variable } & \multirow[t]{2}{*}{$\beta$} & \multirow[t]{2}{*}{$p$} & \multirow[t]{2}{*}{$t$} & \multicolumn{2}{|c|}{ CI (95\%) } & \multirow[t]{2}{*}{ Tolerance } & \multirow[t]{2}{*}{ VIF } \\
\hline & & & & Lower & Upper & & \\
\hline \multicolumn{8}{|l|}{ Block 1} \\
\hline Age & .00 & .989 & .01 & -.04 & .04 & .997 & 1.003 \\
\hline Gender & -.10 & .171 & -1.37 & -1.59 & .29 & .997 & 1.003 \\
\hline \multicolumn{8}{|l|}{ Block 2} \\
\hline Age & -.02 & .803 & -.25 & -.05 & .04 & .989 & 1.011 \\
\hline Gender & -.11 & .144 & -1.47 & -1.60 & .24 & .997 & 1.003 \\
\hline MVD & .22 & .004 & 2.92 & .02 & .08 & .992 & 1.009 \\
\hline
\end{tabular}

\section{Study 2}

\subsection{Method}

\subsubsection{Design and participants}

A cross-sectional correlational design was adopted to explore whether intrasexual competition, mate value discrepancy, experience of sexual infidelity, and self-esteem predicted digital dating abuse. Initially, 150 people took part, but due to extreme missing data and people consenting, but not starting the study, 16 participants' data were removed. The final sample comprised of 134 heterosexual people from the general public in the UK, recruited via Qualtrics (113 women, 21 men, Mage $=31.16$ years old, $S D=10.93)$. Participants also took part via survey links shared on social media sites such as Twitter and Facebook. Participants were required to be English speaking, due to the survey being presented in English. All participants 
consented online. Participants were required to currently be in a romantic relationship (Mrelationship length $=99.19$ months, $S D=97.35$, Median $=69)$.

To guide our anticipated sample size, an a-priori power analysis was conducted using $G^{*}$ Power (Faul et al. 2009). To achieve $80 \%$ power (medium effect size of .15, with 4 predictors, and an alpha level of .05-all for multiple regression), G*Power recommended 85 participants, which we surpassed.

\section{Materials}

\subsection{Mate Value}

We used the same mate value scale used in study 1 . Mate value discrepancy was also calculated in the same manner. The scale was again reliable in our sample (self-mate value, $\alpha$ $=.72$ and partner mate value, $\alpha=.86)$.

\subsubsection{Intrasexual competition}

The 12-item Intrasexual Competition Scale (Buunk \& Fisher, 2009) was used to measure intrasexual competition. Items are measured on a 1 (not at all applicable) to 7 (completely applicable) Likert scale, with higher scores reflecting high intrasexual competition, and low scores reflecting low intrasexual competition. The male version was presented to men, and the female version was presented to women (the items are the same, but the gendered pronouns are sex-specific. For example, the item 'I always want to beat other women.' was presented to women, and the item 'I always want to beat other men' was presented to men. The scale was reliable in our sample $(\alpha=.88)$.

\subsubsection{Self-esteem}


The 10-item Self-esteem (Rosenberg, 1965) scale was used to measure participants' selfesteem. The scale measures an individual's self-esteem, with high values reflecting high selfesteem and lower values reflecting low self-esteem. The scale includes items such as ' $O n$ the whole, I am satisfied with myself'. The scale was reliable in our sample $(\alpha=.85)$.

\subsubsection{Digital Dating Abuse}

We used the same scale used in study 1 . The scale was reliable in our sample $(\alpha=.72)$. Finally, we asked participants if they had experience of sexual infidelity in previous relationships, by asking 'Have you ever been cheated on by a partner?' for which participants could reply 'yes' or 'no'. Seventy-six people had been cheated on and fifty-eight had not been cheated on.

\section{Results}

Descriptive statistics are presented in Table 2. Bivariate Pearson's correlations between all variables are presented in Table 3. Tolerance and VIF values are presented in Table 4 showing that there was no multicollinearity in the model. Table 3 shows that there was a positive, significant relationship between mate value discrepancy and digital dating abuse, in that those who reported greater mate value discrepancies between them, and their partner perpetrated greater levels of digital dating abuse. Furthermore, there was a negative, significant

relationship between self-esteem and mate value discrepancy, in that low mate value discrepancy was associated with high self-esteem.

\subsection{Hierarchical multiple regression}


Hierarchical multiple regression was conducted to predict the perpetration of digital dating abuse from mate value discrepancy, experience of sexual infidelity, self-esteem, and intrasexual competition, whilst controlling for age and gender.

Age and gender were added to block 1, explaining $0.7 \%$ of the variance in digital dating abuse (adjusted $\left.R^{2}=-.009\right), F(2,131)=.430, p=.651$. Mate value discrepancy, self-esteem, experience of sexual infidelity, and self-esteem were added to block 2 of the model. This resulted in a $R^{2}$ change of .115 and a statistically significant $F$ change (.003).

The final model explained $12.1 \%$ of the variance in digital dating abuse, $F(6,127)=$ 2.92 (adjusted $\left.R^{2}=.080\right), p=.011$, Durbin-Watson $=1.83$, Cohens $f^{2}=0.14$. The only significant predictor of digital dating abuse was mate value discrepancy. Again, mate value discrepancy predicted digital dating abuse, in that those who reported greater discrepancies in mate value between them and their partners, engaged in greater levels of digital dating abuse. All other predictors were non-significant in predicting digital dating abuse.

Table 2: Descriptive statistics relating to all key variables

\begin{tabular}{lc}
\hline Variable & Mean $(S D)$ \\
\hline Self-esteem & $21.89(4.33)$ \\
Digital dating abuse & $22.85(3.59)$ \\
Self-mate value & $89.54(9.15)$ \\
Partner mate value & $93.48(13.52)$ \\
Mate value discrepancy & $-3.93(12.79)$ \\
\hline
\end{tabular}


Table 3: Bivariate correlations between digital dating abuse, MVD (mate value discrepancy), self-esteem, and IC (intrasexual competition).

$$
\text { Digital dating abuse MVD IC Self-esteem }
$$

Digital dating abuse

MVD $\quad 0.29 * * *$

$\begin{array}{lll}\text { IC } & 0.13 & 0.09\end{array}$

$\begin{array}{lllll}\text { Self-esteem } & 0.09 & -0.17 * & .04\end{array}$

$* p<.05, * * * p<.001$

Table 4: Results of the multiple regression model predicting digital dating abuse from MVD, self-esteem, previous infidelity, and IC.

\begin{tabular}{|c|c|c|c|c|c|c|c|}
\hline \multirow[t]{2}{*}{ Variable } & \multirow[t]{2}{*}{$\beta$} & \multirow[t]{2}{*}{$p$} & \multirow[t]{2}{*}{$t$} & \multicolumn{2}{|c|}{ CI (95\%) } & \multirow[t]{2}{*}{ Tolerance } & \multirow[t]{2}{*}{ VIF } \\
\hline & & & & Lower & Upper & & \\
\hline \multicolumn{8}{|l|}{ Block 1} \\
\hline Age & -.08 & .374 & -.89 & -.08 & .03 & .999 & 1.001 \\
\hline Gender & .02 & .816 & .23 & -1.50 & 1.90 & .999 & 1.001 \\
\hline \multicolumn{8}{|l|}{ Block 2} \\
\hline Age & -.09 & .328 & -.98 & -.09 & .03 & .898 & 1.113 \\
\hline Gender & .04 & .663 & .44 & -1.30 & 2.03 & .944 & 1.059 \\
\hline Previous & -.03 & .707 & -.38 & -1.46 & .99 & .936 & 1.068 \\
\hline \multicolumn{8}{|l|}{ infidelity } \\
\hline Self-esteem & .13 & .140 & 1.49 & -.04 & .25 & .920 & 1.087 \\
\hline IC & .09 & .332 & .97 & -.03 & .09 & .978 & 1.139 \\
\hline MVD & .31 & $<.001$ & 3.60 & .04 & .13 & .941 & 1.062 \\
\hline
\end{tabular}




\section{Discussion}

The primary aims of this paper were to 1) replicate and further extend the relationship between mate value discrepancy and digital dating abuse with two independent samples and 2) to explore how unexplored, exploratory factors related to digital dating abuse. Our findings show that mate value discrepancy was positively related to digital dating abuse in two independent samples, thus showing that the original finding by Bhogal and Howman (2019) replicates. Furthermore, we find that exploratory variables such as intrasexual competition (hypothesis 2), self-esteem (hypothesis 3) and experienced infidelity (hypothesis 4) were unrelated to digital dating abuse.

Hypothesis 1 was supported, in that large mate value discrepancies predicted digital dating abuse, thus providing further support of the role of mate value discrepancy in digital dating abuse. This finding here provides further support that digital dating abuse is a contemporary mate retention tactic. Due to the importance of replication in psychology (Earp \& Trafimow, 2015), this is an important finding, as evidence now shows that mate value discrepancy predicts digital dating abuse in three studies, including that of Bhogal and Howman (2019). Further key strengths and novel additions of this paper include recruiting a more diverse population to that of Bhogal and Howman (2019). For example, Bhogal and Howman (2019) recruited undergraduate and postgraduate students with a mean age of 22.2 years old, whereas, for both studies included in this paper, the mean ages were higher, and the general public was recruited, as well as students.

\subsection{Outline of findings}

We found that previous infidelity (exploratory variable) was unrelated to digital dating abuse. A limitation of the way we operationalized this variable could be improved on in future research. For example, we asked if participants had been cheated on, but we did not consider 
how many times, and in how many relationships participants had been cheated on. With the advent of digital mediums, research shows that people consider online behaviors involving a sexual element (such as cybersex) to be infidelity, and often experience trauma as a result of being a victim of online infidelity (Schneider, Weiss, \& Samenow, 2012). This shows that perceptions of sexual infidelity are changing with the use of digital mediums. This variable could be extended in future research, with a focus on online and offline infidelity.

Self-esteem (exploratory) was unrelated to the perpetration of digital dating abuse. We propose that this variable should again be explored in future research but operationalized more effectively. For example, Holden, Zeigler-Hill, Shackelford, and Welling, (2018) argue the need for researchers to move beyond viewing self-esteem as a single factor, but rather, we should be viewing self-esteem as multi-faceted by exploring contingent self-esteem (selfworth) and relationship-contingent self-esteem (relationship-focused) when examining the role of self-esteem in the functionality of romantic relationships. In addition to this, future researchers could examine the role of explicit and implicit self-esteem (see Zeigler-Hill et al., 2012) as potential moderators of digital dating abuse and mate retention. A final suggestion in regards to self-esteem is that future researchers could explore the role of secure and fragile self-esteem in relation to digital dating abuse, as opposed to viewing self-esteem as a unified construct (see Zeigler-Hill et al., 2012; Kernis, 2003). Since the Rosenberg (1965) measure used here focuses on explicit self-esteem only (self-worth etc.), future research could focus on implicit self-esteem, which centres on a more internal, intrinsic measure of self-esteem (Zeigler-Hill et al., 2012). Examples of these include the Name-Letter task (Nuttin, 1987).

Intrasexual competition (exploratory) was unrelated to the perpetration of digital dating abuse. One of the reasons why intrasexual competition was not a significant predictor could be because of the age of participants who took part in both studies. Mean ages for both studies were 27 and 31 . However, younger adults are typically more heavier users of digital mediums 
compared to older adults (Correa, Hinsley, \& de Zúñiga, 2010), younger adults are more likely to engage in intimate partner violence and increased mate retention tactics (Marganski \& Fauth, 2013; Pazhoohi, Jahromi, \& Doyle, 2016). As a result, future research examining the role of intrasexual competition in digital dating abuse should aim to recruit a younger adult sample than we gathered here.

Most research exploring intrasexual competition has used the Buunk and Fisher (2009) measure used in this paper. However, researchers have argued and provided psychometric evidence that future research should use more multidimensional measures of intrasexual competition. Karimi-Malekabadi, Ghanbarian, Afhami, and Chegeni, (2019) recently developed a psychometric measure which can be applied to non-Western cultures and also incorporates psychological implications of intrasexual rivalry rather than focusing solely on behavioral aspects of intrasexual competition, as found in the measure used in this study. Karima-Malekabadi et al. (2019) argue that intrasexual rivalry (the sole focus of the Buunk and Fisher, 2009 measure) is only one aspect of intrasexual competition. For example, they argue that self-promotion (such as attractiveness enhancing techniques) can be an intrasexual competitive strategy which does not involve rival derogation. This new theory-driven tool could be used to replicate the findings of study 2 with a more up to date measure of intrasexual competition. This is an important point, as research shows that intrasexual competition involves both rival derogation and increasing ones mate value through attractiveness enhancing techniques, to attract mates, and compete with rivals (Keys \& Bhogal, 2018; Pettijohn II, Pettijohn, \& Gilbert, 2011).

Although scholars have only recently paid attention to digital dating abuse as a form of intimate partner violence, future research should explore the measures which are used to measure digital dating abuse. For example, Brown and Hegarty (2018) have recently provided a critical analysis of the variety of measures which are typically used to measure digital dating 
abuse. Although there is some consistency in the measures used, there is also some disparity between measures. For example, some scales focus more on milder forms of electronic intrusion, while some scales, although incorporating items related to electronic intrusiveness, focus more on cyber aggression, bullying and stalking directed towards romantic partners. The measure used in this study and that of Bhogal and Howman (2019) was the Reed et al. (2016) measure of digital dating abuse. Future research could provide further empirical attention to the role of mate value discrepancy in digital dating abuse by using alternative measures, such as the cyber dating abuse measure created by Borrajo, Gámez-Guadix, Pereda, and Calvete (2015), which has been used in previous research exploring alternative factors which predict digital dating abuse (Deans \& Bhogal, 2017). Considering how digital dating abuse can encompass several intrusive or abusive behaviors, which vary in severity and impact, future research should be mindful of the exact types of behaviors being explored (Brown \& Hegarty, 2018).

\subsection{Limitations}

Although there are strengths to the research presented in this paper, there are also some notable limitations. First, due to the correlational nature of both studies, we are unable to establish cause and effect. Future researchers could explore digital dating abuse and mate retention through experimental studies. Second, generalizability could be an issue, as both our samples were Western, with no application to non-Western cultures. Collecting data from WEIRD samples could limit the applicability of our findings (Henrich, Heine, \& Norenzayan, 2010). Future research could explore digital dating abuse and mate retention in non-Western countries. Third, we did not explore additional variables which may be related to digital dating abuse (and certainly related to mate retention behaviors), such as directly using the mate retention inventory (Buss, Shackelford, \& McKibbin, 2008; Sela et al., 2017) and the Big Five 
personality traits (Atari, Barbaro, Sela, Shackelford, \& Chegeni, 2017). Fourth, since there are sex differences in mate retention, and mating strategies (Buss, 2006), a limitation of this study is that we did not recruit enough men in both studies to conduct viable statistical comparisons by sex. However, although an abundance of literature shows there are sex differences in mating strategies, there is little evidence to suggest that there are sex differences in the perpetration of digital dating abuse. This has been inconsistent in the literature (Bhogal \& Howman, 2019; Brown \& Hegarty, 2018).

\subsection{Conclusion}

This research further bridges the gap between evolutionary science and cyberpsychology by providing an evolutionary perspective to studying online behavior, which is imperative to understanding the online world (Piazza \& Bering, 2009). According to Bhogal and Howman (2019), research exploring the factors associated with digital dating abuse are crucial in increasing awareness of the behaviors associated with digital dating abuse, thus increasing our knowledge, and extending the literature on intimate partner violence, and the varying ways partner violence is evolving with the use of technology. In summary, this study provides further support for the strong role of mate value discrepancy in the perpetration of digital dating abuse amongst those in romantic relationships.

\section{References}

Albert, G., \& Arnocky, S. (2016). Use of Mate retention Strategies. In Encyclopedia of Evolutionary Psychological Science. https://doi.org/10.1007/978-3-319-16999-6_151-1

Arnocky, S., Ribout, A., Mirza, R. S., \& Knack, J. M. (2014). Perceived mate availability influences intrasexual competition, jealousy and mate guarding behavior. Journal of Evolutionary Psychology, 12, 45-64. https://doi.org/10.1556/JEP.12.2014.1.3 
Arnocky, S., Sunderani, S., \& Vaillancourt, T. (2013). Mate-poaching and mating success in humans. Journal of Evolutionary Psychology, 11(2), 65-83.

https://doi.org/10.1556/JEP.11.2013.2.2

Atari, M., Barbaro, N., Sela, Y., Shackelford, T. K., \& Chegeni, R. (2017). The Big Five personality dimensions and mate retention behaviors in Iran. Personality and Individual Differences, 104, 286-290. https://doi.org/10.1016/J.PAID.2016.08.029

Atari, M., Barbaro, N., Shackelford, T. K., \& Chegeni, R. (2017). Psychometric Evaluation and Cultural Correlates of the Mate retention Inventory-Short Form (MRI-SF) in Iran. Evolutionary Psychology, 15(1), 1-11. https://doi.org/10.1177/1474704917695267

Bhogal, M. S., \& Howman, J. M. (2019). Mate Value Discrepancy and Attachment Anxiety Predict the Perpetration of Digital Dating Abuse. Evolutionary Psychological Science, 5(1), 113-120. https://doi.org/10.1007/s40806-018-0172-6

Borrajo, E., Gámez-Guadix, M., Pereda, N., \& Calvete, E. (2015). The development and validation of the cyber dating abuse questionnaire among young couples. Computers in Human Behavior, 48, 358-365. https://doi.org/10.1016/J.CHB.2015.01.063

Brem, M. J., Spiller, L. C., \& Vandehey, M. A. (2015). Online Mate retention Tactics on Facebook Are Associated With Relationship Aggression. Journal of Interpersonal violence, 30(16), 2831-2850. https://doi.org/10.1177/0886260514554286

Brown, C., \& Hegarty, K. (2018). Digital dating abuse measures: A critical review. Aggression and Violent Behavior, 40, 44-59. https://doi.org/10.1016/J.AVB.2018.03.003

Burke, S. C., Wallen, M., Vail-Smith, K., \& Knox, D. (2011). Using technology to control intimate partners: An exploratory study of college undergraduates. Computers in Human Behavior, 27(3), 1162-1167. https://doi.org/10.1016/J.CHB.2010.12.010 
Buss, D. M. (1988). The evolution of human intrasexual competition: Tactics of mate attraction. Journal of Personality and Social Psychology, 54(4), 616-628. http://dx.doi.org/10.1037/0022-3514.54.4.616

Buss, D. M. (2006). Strategies of Human Mating: Psychological topics. Psychological Topics, 15(2), 239-260.

Buss, D. M., \& Barnes, M. (1986). Preferences in human mate selection. Journal of Personality and Social Psychology, 50(3), 559-570.

Buss, D. M., \& Duntley, J. D. (2008). Adaptations for exploitation. Group Dynamics: Theory, Research, and Practice, 12(1), 53-62. https://doi.org/10.1037/10892699.12.1.53

Buss, D. M., \& Shackelford, T. K. (1997). From vigilance to violence: Mate retention tactics in married couples. Journal of Personality and Social Psychology, 72(2), 346-361.

Buss, D. M., Shackelford, T. K., \& McKibbin, W. F. (2008). The Mate retention InventoryShort Form (MRI-SF). Personality and Individual Differences, 44(1), 322-334. https://doi.org/10.1016/j.paid.2007.08.013

Buunk, A. P., \& Fisher, M. (2009). Individual differences in intrasexual competition. Journal of Evolutionary Psychology, 7(1), 37-48. https://doi.org/10.1556/JEP.7.2009.1.5

Correa, T., Hinsley, A. W., \& de Zúñiga, H. G. (2010). Who interacts on the Web?: The intersection of users' personality and social media use. Computers in Human Behavior, 26(2), 247-253. https://doi.org/10.1016/J.CHB.2009.09.003

Daly, M., \& Wilson, M. (1988). Evolutionary Social Psychology and Family Homicide. Science, 242, 519-524. https://doi.org/10.2307/1702049

Danel, D. P., Siennicka, A., Glińska, K., Fedurek, P., Nowak-Szczepańska, N., Jankowska, E. A., ... Lewandowski, Z. (2017). Female perception of a partner's mate value 
discrepancy and controlling behaviour in romantic relationships. Acta Ethologica, 20(1), 1-8. https://doi.org/10.1007/s10211-016-0240-5

Darwin, C. (1871). The descent of man, and selection in relation to sex. London: John Murray.

Deans, H., \& Bhogal, M. S. (2017). Perpetrating Cyber Dating Abuse: A Brief Report on the Role of Aggression, Romantic Jealousy and Gender. Current Psychology. https://doi.org/10.1007/s12144-017-9715-4

Earp, B. D., \& Trafimow, D. (2015). Replication, falsification, and the crisis of confidence in social psychology. Frontiers in Psychology, 6(May), 1-11. https://doi.org/10.3389/fpsyg.2015.00621

Erik, E., \& Bhogal, M. S. (2016). Do the dark triad and self-perceived mate value predict intention to mate poach? Letters on Evolutionary Behavioral Science, 7(2), 1-4. https://doi.org/10.5178/lebs.2016.50

Fahy, A. E., Stansfeld, S. A., Smuk, M., Smith, N. R., Cummins, S., \& Clark, C. (2016). Longitudinal Associations Between Cyberbullying Involvement and Adolescent Mental Health. Journal of Adolescent Health, 59(5), 502-509. https://doi.org/10.1016/J.JADOHEALTH.2016.06.006

Faul, F., Erdfelder, E., Buchner, A., \& Lang, A.-G. (2009). Statistical power analyses using G*Power 3.1: Tests for correlation and regression analyses. Behavior Research Methods, 41(4), 1149-1160. https://doi.org/10.3758/BRM.41.4.1149

Graham-Kevan, N., \& Archer, J. (2009). Control tactics and partner violence in heterosexual relationships. Evolution and Human Behavior, 30(6), 445-452. https://doi.org/10.1016/j.evolhumbehav.2009.06.007 
Henrich, J., Heine, S. J., \& Norenzayan, A. (2010). The weirdest people in the world? Behavioral and Brain Sciences, 33(2 3), 61.

Holden, C. J., Shackelford, T. K., Zeigler-Hill, V., Miner, E. J., Kaighobadi, F., Starratt, V. G., ... Buss, D. M. (2014). Husband's Esteem Predicts his Mate retention Tactics. Evolutionary Psychology, 12(3), 655-672. https://doi.org/10.1177/147470491401200311

Holden, C. J., Zeigler-Hill, V., Shackelford, T. K., \& Welling, L. L. M. (2018). The impact of relationship-contingent self-esteem on mate retention and reactions to threat. Personal Relationships, 25(4), 611-630. https://doi.org/10.1111/pere.12255

JASP Team (2018). JASP (Version 0.8.0.0) [Computer software]

Jonason, P. K., Li, N. P., \& Buss, D. M. (2010). The costs and benefits of the Dark Triad: Implications for mate poaching and mate retention tactics. Personality and Individual Differences, 48(4), 373-378. https://doi.org/10.1016/J.PAID.2009.11.003

Karimi-Malekabadi, F., \& Esmaeilinasab, M. (2019). Religiosity, intrasexual rivalry, and mate retention behaviors in Iran. Personality and Individual Differences, 149, 135-140. https://doi.org/10.1016/J.PAID.2019.05.059

Karimi-Malekabadi, F., Ghanbarian, E., Afhami, R., \& Chegeni, R. (2019). Theory-Driven Assessment of Intrasexual Rivalry. Evolutionary Psychological Science, 5(3), 286-293. https://doi.org/10.1007/s40806-018-00185-7

Kernis, M. H. (2003). Toward a Conceptualization of Optimal Self-Esteem. Psychological Inquiry, 14, 1-26. https://doi.org/10.2307/1449033

Keys, E., \& Bhogal, M. S. (2018). Mean Girls: Provocative Clothing Leads to Intra-Sexual Competition between Females. Current Psychology, 37(3). https://doi.org/10.1007/s12144-016-9536-x

Kirsner, B. R., Figueredo, A. J., \& Jacobs, W. J. (2003). Self, friends, and lovers: structural 
relations among Beck Depression Inventory scores and perceived mate values. Journal of Affective Disorders, 75(2), 131-148. https://doi.org/10.1016/S0165-0327(02)00048-4

Lewis, S. F., Travea, L., \& Fremouw, W. J. (2002). Characteristics of female perpetrators and victims of dating violence. Violence and Victims, 17(5), 593-606.

Lopes, G. S., Shackelford, T. K., Santos, W. S., Farias, M. G., \& Segundo, D. S. A. (2016). Mate retention Inventory-Short Form (MRI-SF): Adaptation to the Brazilian context. Personality and Individual Differences, 90, 36-40.

https://doi.org/10.1016/J.PAID.2015.10.033

Marganski, A., \& Fauth, K. (2013). Socially Interactive Technology and Contemporary Dating. International Criminal Justice Review, 23(4), 357-377. https://doi.org/10.1177/1057567713513797

Marr, J. C., Thau, S., Aquino, K., \& Barclay, L. J. (2012). Do I want to know? How the motivation to acquire relationship-threatening information in groups contributes to paranoid thought, suspicion behavior, and social rejection. Organizational Behavior and Human Decision Processes, 117(2), 285-297. https://doi.org/10.1016/J.OBHDP.2011.11.003

Melander, L. A. (2010). College Students' Perceptions of Intimate Partner Cyber Harassment. Cyberpsychology, Behavior, and Social Networking, 13(3), 100722182519069. https://doi.org/10.1089/cpb.2009.0221

Miner, E. J., Starratt, V. G., \& Shackelford, T. K. (2009). It's not all about her: Men's mate value and mate retention. Personality and Individual Differences, 47(3), 214-218. https://doi.org/10.1016/J.PAID.2009.03.002

Murray, S. L., Rose, P., Bellavia, G. M., Holmes, J. G., \& Kusche, A. G. (2002). When rejection stings: How self-esteem constrains relationship-enhancement processes. 
Journal of Personality and Social Psychology, 83(3), 556-573.

https://doi.org/10.1037/0022-3514.83.3.556

Nuttin, J. M. (1987). Affective consequences of mere ownership: The name letter effect in twelve European languages. European Journal of Social Psychology, 17(4), 381-402. https://doi.org/10.1002/ejsp.2420170402

Pallant, J. (2016). SPSS Survival Manual. Open University Press.

Pazhoohi, F., Jahromi, A. S., \& Doyle, J. F. (2016). Mate retention Tactics Decline with Age of Iranian Men. Evolutionary Psychological Science, 2(3), 165-170. https://doi.org/10.1007/s40806-016-0046-8

Pettijohn II, T. F., Pettijohn, T. F., \& Gilbert, A. G. (2011). Romantic Relationship Status and Gender Differences in Sun Tanning Attitudes and Behaviors of U.S. College Students. Psychology, 02(02), 71-77. https://doi.org/10.4236/psych.2011.22012

Piazza, J., \& Bering, J. M. (2009). Evolutionary cyber-psychology: Applying an evolutionary framework to Internet behavior. Computers in Human Behavior, 25(6), 1258-1269. https://doi.org/10.1016/J.CHB.2009.07.002

Reed, L. A., Tolman, R. M., \& Safyer, P. (2015). Too close for comfort: Attachment insecurity and electronic intrusion in college students' dating relationships. Computers in Human Behavior, 50, 431-438. https://doi.org/10.1016/J.CHB.2015.03.050

Reed, L. A., Tolman, R. M., \& Ward, L. M. (2017). Gender matters: Experiences and consequences of digital dating abuse victimization in adolescent dating relationships. Journal of Adolescence, 59, 79-89. https://doi.org/10.1016/j.adolescence.2017.05.015

Reed, L. A., Tolman, R. M., Ward, L. M., \& Safyer, P. (2016). Keeping tabs: Attachment anxiety and electronic intrusion in high school dating relationships. Computers in Human Behavior, 58, 259-268. https://doi.org/10.1016/J.CHB.2015.12.019 
Rhoades, G. K., Kamp Dush, C. M., Atkins, D. C., Stanley, S. M., \& Markman, H. J. (2011). Breaking up is hard to do: The impact of unmarried relationship dissolution on mental health and life satisfaction. Journal of Family Psychology, 25(3), 366-374. https://doi.org/10.1037/a0023627

Schneider, J. P., Weiss, R., \& Samenow, C. (2012). Is It Really Cheating? Understanding the Emotional Reactions and Clinical Treatment of Spouses and Partners Affected by Cybersex Infidelity. Sexual Addiction \& Compulsivity, 19(1-2), 123-139. https://doi.org/10.1080/10720162.2012.658344

Sela, Y., Mogilski, J. K., Shackelford, T. K., Zeigler-Hill, V., \& Fink, B. (2017). Mate Value Discrepancy and Mate retention Behaviors of Self and Partner. Journal of Personality, 85(5), 730-740. https://doi.org/10.1111/jopy.12281

Selya, A. S., Rose, J. S., Dierker, L. C., Hedeker, D., \& Mermelstein, R. J. (2012). A Practical Guide to Calculating Cohen's f2, a Measure of Local Effect Size. https://doi.org/https://doi.org/10.3389/fpsyg.2012.00111

Shackelford, T. K., Goetz, A. T., \& Buss, D. M. (2005). Mate retention in marriage: Further evidence of the reliability of the Mate retention Inventory. Personality and Individual Differences, 39(2), 415-425. https://doi.org/10.1016/J.PAID.2005.01.018

Sidelinger, R. J., \& Booth-Butterfield, M. (2007). Mate Value Discrepancy as Predictor of Forgiveness and Jealousy in Romantic Relationships. Communication Quarterly, 55(2), 207-223. https://doi.org/10.1080/01463370701290426

Stonard, K. E., Bowen, E., Walker, K., \& Price, S. A. (2017). “They'll Always Find a Way to Get to You": Technology Use in Adolescent Romantic Relationships and Its Role in Dating Violence and Abuse. Journal of Interpersonal Violence, 32(14), 2083-2117. https://doi.org/10.1177/0886260515590787 
Vaillancourt, T. (2013). Do human females use indirect aggression as an intrasexual competition strategy? Philosophical Transactions of the Royal Society B: Biological Sciences, 368(1631), 20130080. https://doi.org/10.1098/rstb.2013.0080

World Health Organisation. (2012). Intimate partner violence: Understanding and addressing violence against women. https://www.who.int/reproductivehealth/publications/violence/rhr12_36/en/

Zeigler-Hill, V., Fulton, J. J., \& Mclemore, C. (2011). The role of unstable self-esteem in the appraisal of romantic relationships, Personality and Individual Differences, 51(1), 5156. https://doi.org/10.1016/j.paid.2011.03.009

Zeigler-Hill, V., Fulton, J. J., \& McLemore, C. (2012). Discrepancies Between Explicit and Implicit Self-Esteem: Implications for Mate retention Strategies and Perceived Infidelity. The Journal of Social Psychology, 152(6), 670-686. https://doi.org/10.1080/00224545.2012.688778

Zweig, J. M., Dank, M., Yahner, J., \& Lachman, P. (2013). The Rate of Cyber Dating Abuse Among Teens and How It Relates to Other Forms of Teen Dating Violence. Journal of Youth and Adolescence, 42(7), 1063-1077. https://doi.org/10.1007/s10964-013-9922-8 